\title{
Propagation and Non-propagation of Small Fatigue Cracks
}

KEISUKE TANAKA and YOSHIAKI AKINIWA Department of Engineering Science, Kyoto University, Kyoto 606, Japan

\section{ABSTRACT}

The propagation and non-propagation of sma1l fatigue cracks at the notch root were studied in the first part of the present paper. A resistancecurve method was proposed for predicting the growth threshold of mechanically short cracks on the basis of the experimental results on the development of crack closure. The effects of material, notch geometry, and mean stress on the growth threshold of short cracks and the notch fatigue strength were successfully predicted by the resistance-curve method. I the second part, the propagation behaviour of small fatigue cracks in smooth specimens was examined. A micromechanical model of small crack growth was combined with statistical simulation of crack growth for life prediction. The fatigue failure diagram threshold condition for siall crack growth.

\section{KEYWORDS}

Fatigue (materials); fracture mechanics; small cracks; crack propagation; crack closure; threshold condition; notch effect; microstructure

\section{INTRODUCTION}

Linear elastic fracture mechanics (LEFM) is a well-established discipline for assessing the strength and durability of a structural component containing cracks and subjected to cyclic loading. The use of $\Delta \mathrm{K}$-based conventional methodology, however, is questionable when the crack length is physically short or less than about $2 \mathrm{~mm}$. Physically small fatigue crack in non-corrosive environments can be classified into three categories: microstructurally small cracks, mechanically small cracks, and large crack (Suresh et al., 1984, Tanaka, 1987).

Large cracks whose lengths are above approximately ten times the grain size are treated by conventional fracture mechanics. Microstructurally small cracks with length on the order of a grain size show anomalously high ir 
regular growth rates. Because of microstructural inhomogeneities, the crack growth behaviour has statistical characteristics. For mechanically mechanics parameters such as the effective range of the stress intensity factor $(\mathrm{SIF}), \Delta \mathrm{K}_{\text {f }}$, or the $\mathrm{J}$ integral range, $\Delta \mathrm{J}$, will give the same growth equation as large cracks, because the material is now regarded as homogeneous. The predictive method of the development of crack closure with crack growth needs to be developed for various loading conditions.

In the first half of the present paper, the propagation and non-propagation of small fatigue cracks at the notch root were treated. The effects of notch geometry, loading conditions and materials on the development of crack closure were modeled. A resistance-curve method was proposed to predict the growth behaviour of small fatigue cracks. In the second part, the propagation behaviour of small fatigue cracks in smooth specimens was ex amined. A micromechanical model of small crack growth was combined with statistical simulation of crack growth for life prediction. The physica

condition of nucleated cracks.

\section{SMALL FATIGUE CRACKS IN NOTCHED SPECIMENS}

\section{Resistance-Curve Method}

The propagation rate of a short fatigue crack nucleated at the root of a sharp notch first decreases as the crack propagates. The crack then becomes non-propagating under low stresses, while it begins to accelerate after reaching a minimum growth rate under high stresses. The SIF value for a crack of length $c$ at the notch root is expressed as

$$
\mathrm{K}=\sigma \sqrt{\pi \mathrm{c}} \mathrm{F}(\mathrm{c})
$$

where $\sigma$ is the nominal stress and $F(c)$ is the geometrical correction factor (Tanaka et al., 1983, 1988a). Since SIF is an increasing function of crack length under a constant applied stress, $\Delta K$-based conventional fracture mechanics fails to predict a dip in the growth rate of a crack at notches. Recent experimental data have shown that $\Delta K_{\text {eff }}$ decreases with crack growth because of the increase of crack clasure, and that the growth rate of short cracks is a unique function of $\Delta \mathrm{K}$ ff, irrespective of crack length and stress amplitude (Tanaka et al., 19\$3, Nishikawa et al., 1986, Akiniwa et al., 1988d, e). A method to estimate the development of crack closure

The development of crack closure was measured for center-notched plate (CNP) specimens with different notch-root radii and single-edge-notched (SEN) specimens with different notch depths. The material was a structural strength was $194 \mathrm{MPa}$. The B with a ferrite grain size of $64 \mu \mathrm{m}$. The yield amplitude with the stress ratio $R=-1$. The crak onder constant load mined in the stress-strain curve enlarged after subtracting the was deter elastic part. The strain signal was the output of the signal of the crack opening displacement.

Figure 1 indicates the change of the opening stress intensity factor $\mathrm{K}_{\mathrm{op}}$ with the crack length (measured on the specimen surface) for two cases of CNP specimens. The final data corresponding to the longest crack length were obtained from non-propagating cracks. The $\mathrm{K}_{\mathrm{op}}$ value increases with

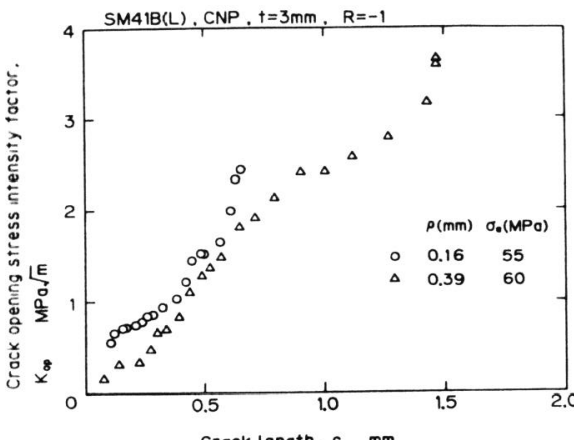

crack length , c mm

Fig. 1. Change of crack opening stress intensity factor with crack length for CNP specimen of mild steel.

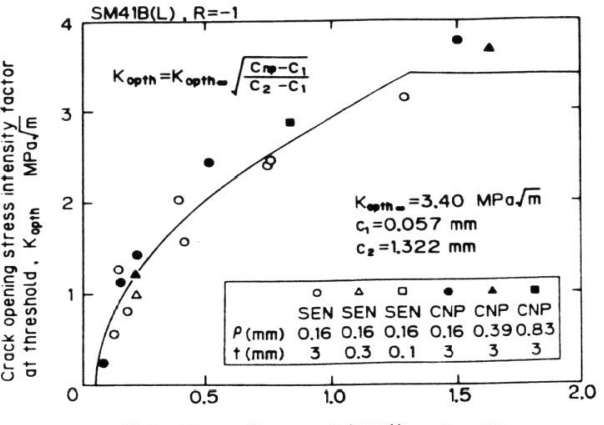

Non-propogating crack length, $\mathrm{cm}_{\mathrm{m}} \mathrm{mm}$

Fig. 2. Change of crack opening stress intensity factor with crack leng mild steel.

increasing crack length. A sharp rise in $K_{\text {op }}$ seen near the threshold may be induced by asperity contact or oxide debrls on the fracture surface.

In Fig. 2, all the data of the $\mathrm{K}_{\mathrm{op}}$ value obtained from non-propagating cracks are plotted against the crack length for the cases of CNP and SEN specimens with various notch depths and root radii. For longer cracks, $\mathrm{K}_{\text {opth }}$ is equal to $\mathrm{K}_{\text {optho }}(=2.78 \mathrm{MPa} / \mathrm{m})$ for long cracks obtained using the The relation between $K_{o p t h}$ and $c_{n p}$ can be approximated ${ }^{\circ}$

$$
\mathrm{K}_{\text {opth }}=\mathrm{K}_{\text {opth }}\left(\frac{\mathrm{c}_{\mathrm{np}}-\mathrm{c}_{1}}{c_{2}-c_{1}}\right)^{1 / 2}
$$

where $c_{1}$ is taken as the length of Stage I crack $(0.057 \mathrm{~mm})$, and $c_{2}$ is the crack length $(1.322 \mathrm{~mm})$ above which $\mathrm{K}_{\mathrm{Opth}}=\mathrm{K}_{\mathrm{Opth}} \mathrm{c}^{\circ}$ The $\mathrm{c}_{2}$ value was determined through a least-square regression method. For the cases of propagating cracks, $K_{O p}$ is lower than that given by eq.(2).

The threshold values of the stress intensity range $\Delta K_{t h}$ and the effective stress intensity range $\Delta K_{\text {effth }}$ are plotted against the non-propagating
crack length in Fig.3(a), where

$$
\Delta \mathrm{K}_{\text {effth }}=\mathrm{K}_{\text {maxth }}-\mathrm{K}_{\text {opth }}
$$

and $K_{\text {math }}$ is the maximum stress intensity factor at the threshold. Barred marks in the figure indicate part-through Stage II cracks and for these cases the abscissa is the equivalent crack length. It should be noted that an intrinsic resistance of the material, $i . e$. $\Delta \mathrm{K}$ ef $\mathrm{fth}$ is nearly constant for all the cracks measured. A decrease in $\Delta k_{\text {th }}$ for short cracks is caused solely by an extrinsic fact
responds to $\Delta K_{\text {th }}$ given by

$$
\Delta \mathrm{K}_{\mathrm{th}}=2 \mathrm{~K}_{\text {maxth }}=2\left[\Delta \mathrm{K}_{\text {effth }}+\mathrm{K}_{\mathrm{opth}}\right]
$$




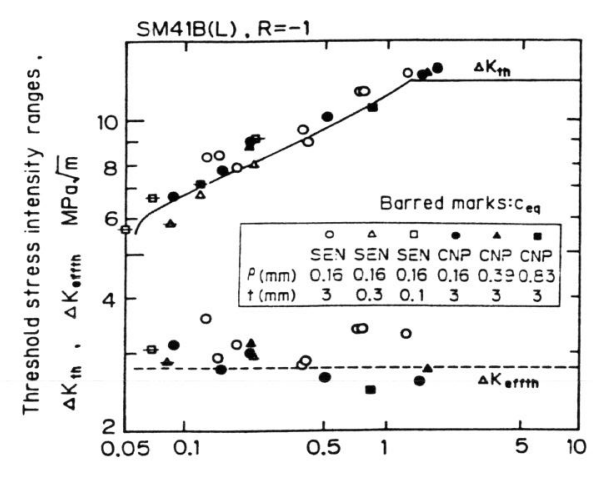

Non-propagating crack length . $\mathrm{c}_{\infty} \mathrm{mm}$

(a) $\Delta \mathrm{K}_{\mathrm{th}}, \Delta \mathrm{K}_{\mathrm{effth}}$ vs. c

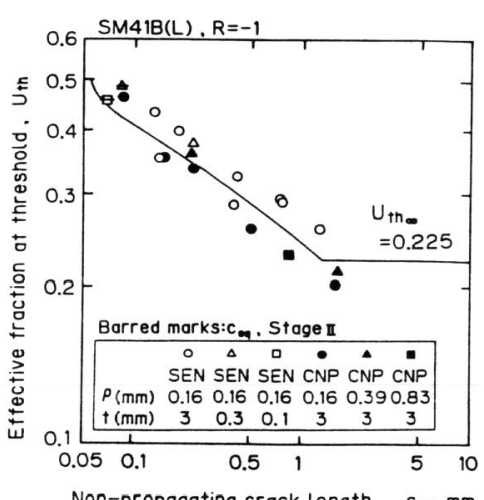

(b) $\mathrm{U}_{\text {th }}$ vs.
Fig. 3. Changes of threshold stress intensity ranges and opening fraction with crack length for mild and open.

where $\Delta K_{\text {effth }}=\Delta K_{\text {ef } f \text { th }}$ and $K_{\text {opth }}$ is determined by eq. (2). The data of $\Delta K_{\text {th }}$ for part-through cracks as well as through cracks follow the solid line. defined by

$$
\mathrm{U}_{\mathrm{th}}=\Delta \mathrm{K}_{\mathrm{effth}} / \Delta \mathrm{K}_{\mathrm{th}}
$$

The $U_{\text {th }}$ value is 0.5 for short cracks, and gradually decreases approaching a constant value of $U_{\text {tho }}=0.225$.

The resistance curve (R-curve) method can be applied to predict the threshold of crack growth of notched component (McEvily et al., 1987, Tanaka et al., 1988a). In Fig.4, the $R$ curve is constructed in terms of the maxi-

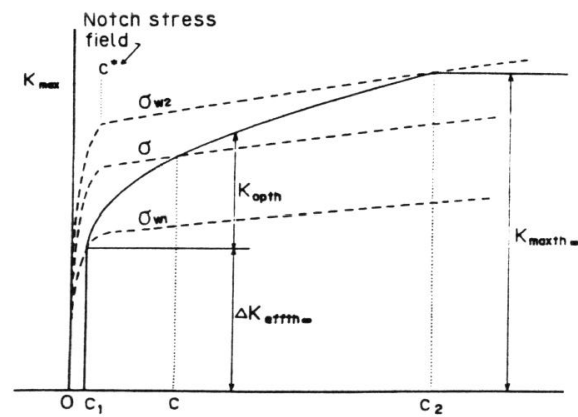

Fig. 4. Resistance-curve method for fatigue crack growth threshold. mum stress intensity factor which is given by

$$
\mathrm{K}_{\operatorname{maxth}}=\Delta \mathrm{K}_{\text {effth }}+\mathrm{K}_{\text {opth }}
$$

The change of the applied $\mathrm{K}_{\max }$ under a given value of the applied nominal stress is shown with the dashed line. A Stage II crack can be formed at the notch root when the stress is larger than $\sigma_{w l}$, and it continues to propagate when the stress is larger than 02 . A non-propagating crack is formed for stresses between $\sigma_{w 1}$ and $\sigma_{w 2}$. The effects of the loading mode and the specimen geometry on $\sigma_{w 1}$ and $\sigma_{W 2}$ are taken into account by the $F$ term in eq.(1). The relation between $k_{o p t h}$ and $c$ changes depending on the stress ratio as well as the material as lescribed below. Once the K value is determined as a function of the crack length, the R-curve method can be used to judge the propagation and non-propagation of short cracks at

\section{Notch-Geometry Effect}

The R-curve method is applied to the CNP specimen with various notch-root radii (Tanaka et al., 1988a). The non-propagating crack length at the intersection between the driving force curve of $\mathrm{K}_{\max }$ and the resistance curv Fig. 5 axthor the case of $\rho=0.16 \mathrm{~mm}$, the diaglim is divid amplitude $\sigma_{a}$ in regions: Regions I, II, and III. When $\sigma_{\mathrm{f}}$ is above $\sigma_{\mathrm{w} 2}$ in Region II, a nucleated crack continues to propagate. Then $\sigma_{a}$ is between $\sigma_{w 1}$ and $\sigma_{w 2}$, a nucleated crack will be arrested at the crack length on the boundary between Regions I and III. On the other hand, Region III will disappear in the case of $\rho=3 \mathrm{~mm}$ as shown in Fig.5(b). The fatigue limit for crack initiation $\sigma_{w 1}$ is higher than that for fracture $\sigma_{w 2}$. Even for this case, a tiny little (microscopic) Stage II crack can be wormed.

The data on the non-propagating crack length are compared with the model prediction in Fig.6, where the solid marks indicate the equivalent length of Stage I cracks and the open marks the length of Stage II cracks. The

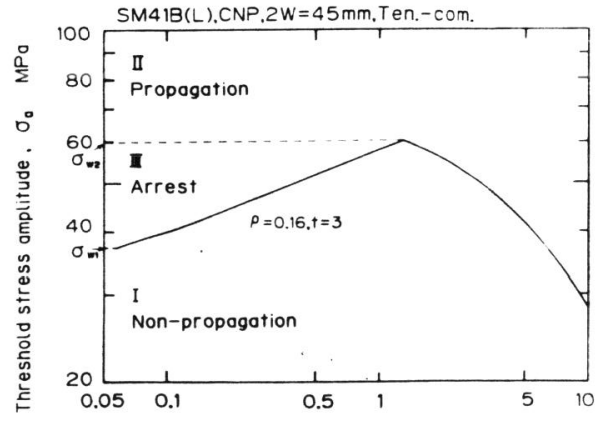

Non-propogating crack length . $c_{\infty}$ m

(a) $\rho=0.16 \mathrm{~mm}$ and $t=3 \mathrm{~mm}$

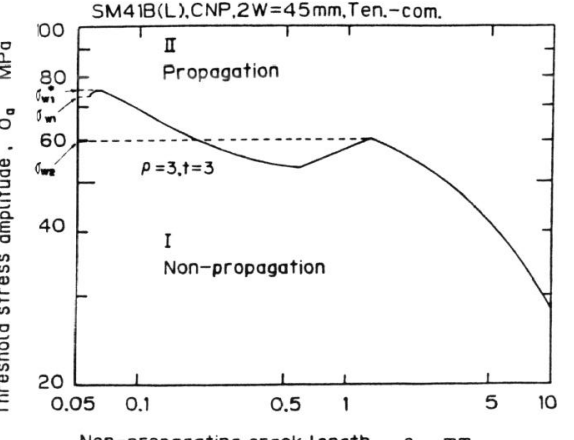

Fig. 5. Fatigue failure diagram for CNP specimen of mild steel. 


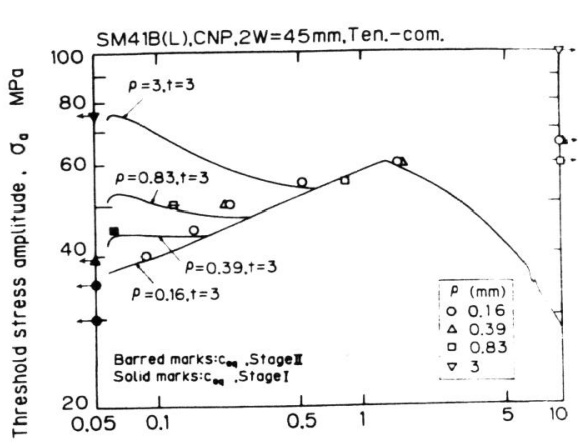

Non-propagating crack length . $c_{\mathrm{np}} \mathrm{mm}$

Fig. 6. Limiting curves for non-propagation of fatigue mild stee1.

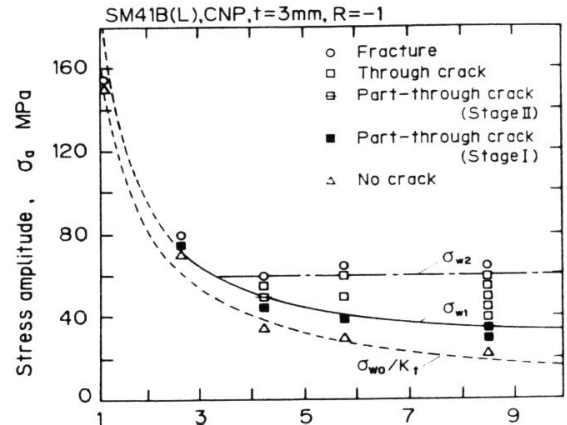

Stress concentration factor. $\mathrm{K}$,

Fig. 7. Relation between fatigue limits and stress concentration points with right-pointing arrows on the ordinate on the right-hand side mean the crack causing fracture. All the data for Stage II cracks fall very well on the predicted lines. The fatigue limits for fracture $\sigma_{w}$ and for Stage II crack initiation $\sigma_{w 1}$ are nicely predicted by the model. ${ }^{\text {W } 2}$ The value and the corresponding non-propagating crack length are independent of the notch-root radius. For the case of $\rho=3 \mathrm{~mm}$, only Stage I crack was formed. Below $\sigma_{w 1}$, Stage I cracks can be formed at the notch root and then arrested. The stress required for the formation of Stage I cracks seems to be lower, and a different criterion will be necessary.

The values of $\sigma_{w 1}$ and $\sigma_{w 2}$ are showr as a function of the elastic stress concentration factor $K_{t}$ in Fig.7, together with the fatigue limit of smooth specimens divided by $K_{t}$. The $\sigma_{w 2}$ value is higher than $\sigma_{w 1}$ for the cases of $\mathrm{K}_{t}$ larger than 3.35 or notch root radii smaller than $1.54 \mathrm{~mm}$. This value for the critical root radius is larger than the value reported by Nisitani (1981), because of a larger grain size of the present material. The data of $\sigma_{\mathrm{w}}$ and $\sigma_{\mathrm{w} 2}$ for these cases follow the predicted lines. For the case of
$\mathrm{K}_{\mathrm{t}}=2.65$, a tiny non-propagating crack is formed. Even for smooth

specimens, a tiny non-propagating crack is seen at the fatigue 1imit, and that the fatigue limit is determined by the propagating condition of this tiny fatigue crack as described later. for the case of $\rho=3 \mathrm{~mm}$.

The R-curve method was applied to predict the fatigue threshold of the SEN The R-curve wethod was applied to iredict the fatigue between prediction and experiment (Tanaka et al. 1988a). Further the che changes of $\sigma_{W l}$ and $\sigma_{W 2}$ with notch size varied keeping the notch root radius at a constant value of $0.16 \mathrm{nn}$, and (ii) the radius of a circular hole was varied. Figure 8 (a) presents the result of the former case, where the stress amplitude on the ordinate means the gross stress amplitude. $\sigma_{w 2}$ is always larger than $\sigma_{w 1}$. The values of $\sigma_{w 1}$ and $\sigma_{w 2}$ for the case of a vanishing notch are 208 and $215 \mathrm{MPa}$, respectively. When the half notch length is below $0.047 \mathrm{~mm}$, $\sigma_{w 2}$ is larger than $\sigma_{w 0}(=163 \mathrm{MPa})$. The notch smaller than this size does not influence the fatigue limit of the specimen,
Half notch length, $t \mathrm{~mm}$

(a) Fatigue limits vs. notch length

Fig. 8.

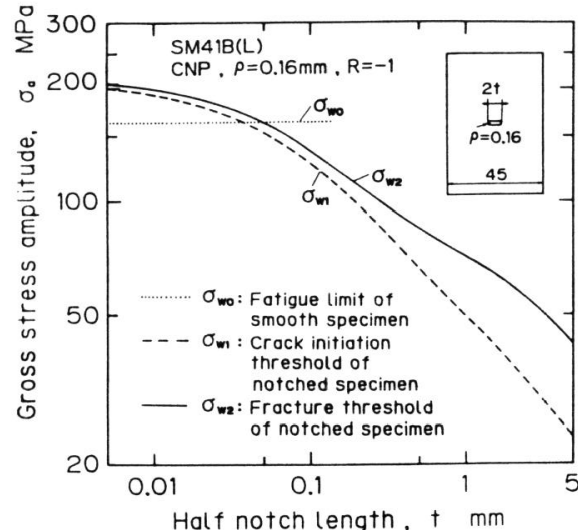

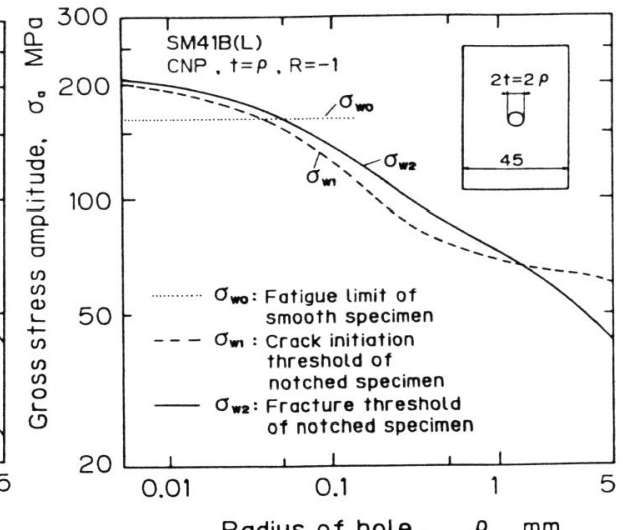

Radius of hole, $\rho \mathrm{mm}$ (b) Fatigue limit vs. hole radius size on fatigue limits.

i.e. the notch is non-damaging. A similar trend is seen for the case of a i.e. the notch is non-danaging. $8(\mathrm{~b})$. Moreover, it is interesting to note that the relative magnitude of $\sigma_{w 1}$ to $\sigma$ changes at the radius of $1.33 \mathrm{~mm}$ The fatigue limit of notched specimens is controlled by the propagation of The fateated crack for smaller holes, while by the nucleation of a crack for larger holes. The existence of non-damaging notches was reported for steels by Murakami et al. (1980). The reason why $\sigma_{w 0}$ can be lower than $\sigma_{w l}$ or $\sigma$ for very small notches will be that the length of Stage I crack in smooth specimens is larger than that in notched specimens.

\section{Material Effect}

The $K_{\text {opth }}$ value as a function of the non-propagating crack length was obtained for the same steel SM41B(S) with a smaller grain size and a 2024-T3 aluminum alloy using SEN specimens $(\rho=0.16 \mathrm{~mm}, t=3 \mathrm{~mm})$ under $R=-1$. The stee has a grain size of $14 \mu \mathrm{m}$ and a yield strength of $280 \mathrm{MPa}$. The grain size
$2024-\mathrm{T} 3$ alloy was $42 \mu \mathrm{m}$ in the rolling direction, $27 \mu \mathrm{m}$ in the transverse 2024-T3 alloy was $42 \mu \mathrm{m}$ in the rolling direction, $27 \mu \mathrm{m}$ in the transverse direction, and $19 \mu \mathrm{m}$ in the thickness direction. The rolling direction parallel to the loading Figure 9 shows the relation between $\mathrm{K}_{\mathrm{opth}}$ and $\mathrm{c}_{\mathrm{np}}$ for two materials. The
rising part of $\mathrm{K}_{\text {opth }}$ with $\mathrm{c}_{\mathrm{np}}$ can be approximated by eq.(2). Both $\mathrm{c}_{1}$ and $c_{2}$ for fine grain-sized steel $\left(c_{1}=0.051 \mathrm{~mm}, c_{2}=0.465 \mathrm{~mm}\right)$ are smaller than those for coarse grain-sized steel shown in Fig.2. For aluminum alloy, they are even smaller $\left(c_{1}=0.034 \mathrm{~mm}\right.$ and $\left.c_{2}=0.374 \mathrm{~mm}\right)$. It is very interesting the $y$ are even smaller $\left(c_{1}=0.034 \mathrm{~mm}\right.$ and $\left.c_{2}=0.374 \mathrm{~mm}\right)$. I ${ }^{1} /_{2}$ is very is identical for three materials.

\section{Mean-Stress Effect}

The behaviour of crack closure is influenced by the plastic deformation 


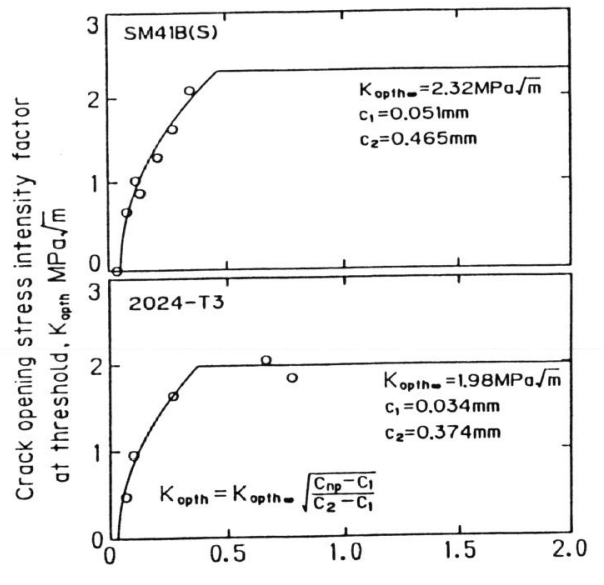

Non-propagating crack length, $\mathrm{c}_{\mathrm{np}} \mathrm{m}$

(a) $\mathrm{K}_{\text {opth }}$ vs. $\mathrm{c}_{\mathrm{np}}$

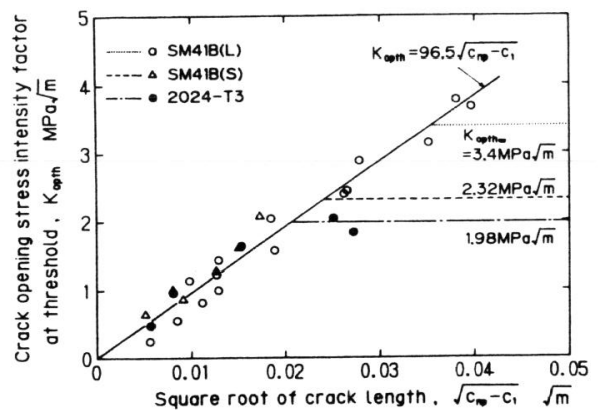

(b) $\mathrm{K}_{\text {opth }}$ vs. $\left(\mathrm{c}_{\left.\mathrm{np}^{-\mathrm{c}_{1}}\right)^{1 / 2}}\right.$
Fig. with crack 1ength at the threshold for mild steels and 2024-T3 aluminum a11oy.

formed near the notch root by stress concentration. Even under cyclic compressive loads, a fatigue crack can grow by the tensile residual stress due to plastic contraction at the notch root under the minimum (compressive) stress (Holm et al., 1986, Akiniwa et al., 1988d, e). The opening stress intensity factor $K_{0}$ as a function of the crack length is mainly controlle by the minimum stress level. The crack opening stress can be calculated assuming that a fatigue crack closes completely at the minimum applied stress and that compressive plastic deformation takes place as if ther were no crack (Tanaka et al., 1986a).

The above assumption can be examined by Newman's type simulation (Newman, 1982) of the development of plasticity-induced crack closure. The simulation was conducted for a center-holed plate (the hole diameter $=6 \mathrm{~mm}$, the plate width $=45 \mathrm{~mm}$ ) of mild steel with a yield strength shows the change of the crack opening stress $\sigma_{\mathrm{op}}=-120 \mathrm{MPa}$. The $\sigma$ value at for the cases of the mine and is given by

$$
\sigma_{\mathrm{op}}=\sigma_{\mathrm{Y}} / \mathrm{K}_{\mathrm{t}}+\sigma_{\mathrm{min}}
$$

where $K_{t}$ is the stress concentration factor for a notch $\left(K_{t}=2.65\right)$. For the cases of $\sigma_{\max }=6 \mathrm{MPa}$ or less, $\sigma_{o p}$ increases up to zero at the boundary of the

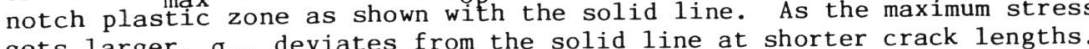

The stress distributions within the plastic zone at the minimum applied stress at crack lengths $c=0,0.749,1.499 \mathrm{~mm}$ for the case of $R=-1$ are shown in Fig.11. At $c=0.749 \mathrm{~mm}$, the stress distribution is identical to that

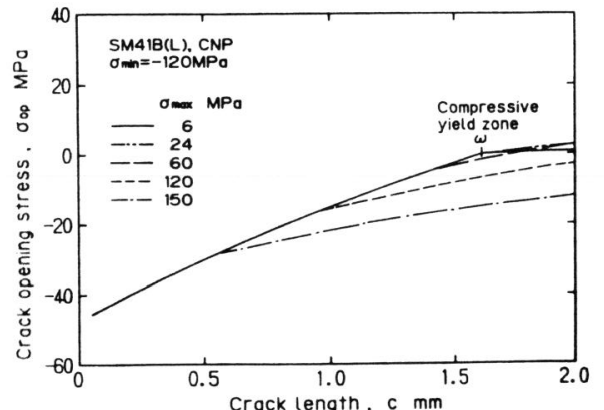

Fig. 10. Change of crack opening stress with crack length obtained by simulation for the case of $\sigma_{\min }=-120$ and various $\sigma_{\max }^{m i n}$ values.

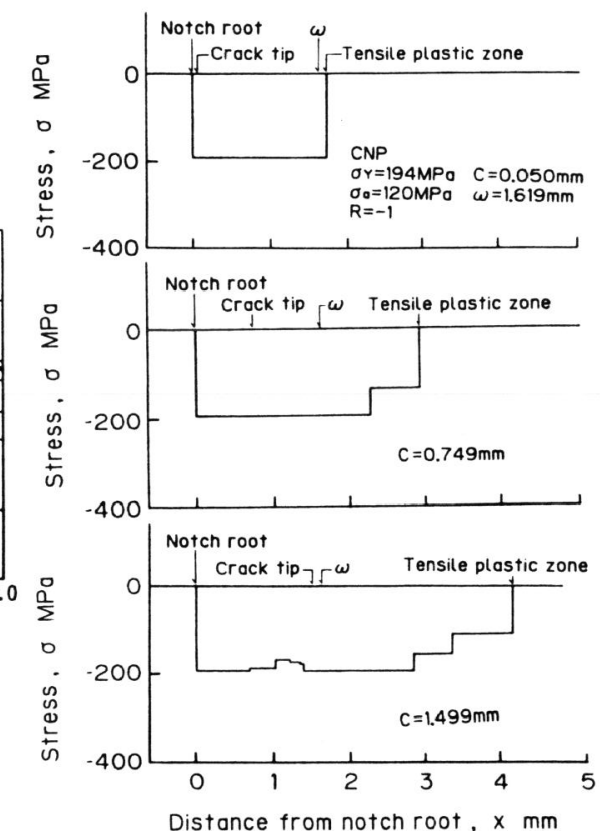

Fig. 11. Stress distributions around a crack obtained by simulation at the minimum applied stress.

without any crack. At $c=1.499 \mathrm{~mm}$, compressive yielding does not extend over the entire crack face, although the crack closes completely.

For general cases, once the stress distribution near the notch root at the minimum applied stress is known, the crack opening stress is predicable. Figure 12 shows the result for SEN specimens of mild steel with a notch zone calculated at the minimum applied stress $-220 \mathrm{MPa}$ by the finite element method was $1.75 \mathrm{~mm}$. The most of the data lie close to the predicted line. There is no sharp rise in $\mathrm{K}_{\mathrm{op}}$ when a crack stops within the compressive plastic zone.

The relation between $K_{o p t h}$ and $c_{n p}$ for various stress ratios can be obtained by superposing the crack closure due to notch-plasticity on that due to crack itself, i.e. crack-tip plasticity, roughness and oxide debris (Akiniwa et al., 1988e). The opening stress intensity factor will be given by the sum of $\mathrm{K}_{\mathrm{opth} 1}$ and $\mathrm{K}_{\mathrm{opth} 2}$ corresponding to two types of crack closure.

$$
\mathrm{K}_{\text {opth }}=\mathrm{K}_{\text {opth1 }}+\mathrm{K}_{\text {opth2 }}
$$

Figure 13 shows the relation between $k_{\text {opth }}$ and $c_{n p}$ obtained from SEN specimens of mild steel (SM41B) under various stress ratios. The $K_{\text {optho }}$ 


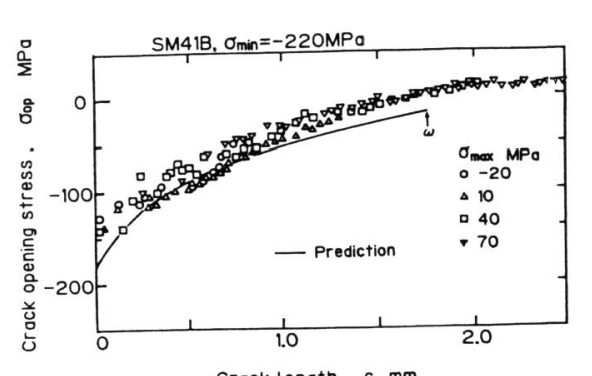

Crack length, $c \mathrm{~mm}$

Fig. 12. Change of crack opening stress with steel under compressive mean stresses.

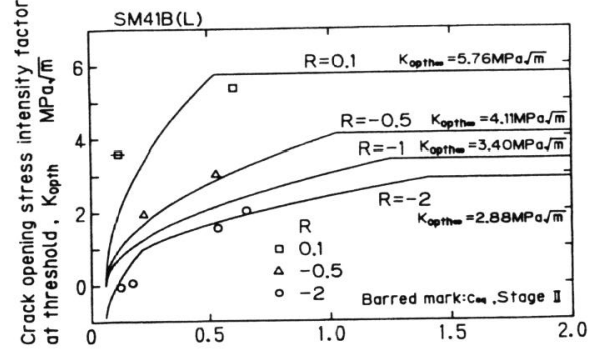

Non-propagating crack length . $c_{\mathrm{cm}} \mathrm{mm}$

Fig. 13. Change of opening stress intensity range with crack length at the threshold for mild steel under various stress ratios.

value for long cracks increases linearly with increasing $R$ value. The $c_{2}$ value also gets shorter. Only for the case of $R=-2$, the effect of notch plasticity is superposed. The experimental data agree with of notched The length of non-propagating cracks and the fatigue limit of specimen for fracture under various stress $\mathrm{K}_{\text {opth }}$ versus $\mathrm{c}_{\mathrm{np}}$ relation given the basis
in Fig. 13 .

SMALL FATIGUE CRACKS IN SMOOTH SPECIMENS

\section{Propagation Behaviour of Small Cracks}

Fatigue cracks nucleated in smooth specimens first grow in an irregular maner manner because of nucleated at an inclusion in a smooth propagation of alloy (Akiniwa et al., 1988b). The propagaspecimath tion rate (The crack length is the length of the projection of a crack on cent (The applied stress axis.) The crack growing the plane perpend is often decelerated when it hits the grain boundary and inclusions or when it makes a sharp bend.

Figure $15(a)$ shows the da/dN vs. a relation obtained from 40 cracks for the stress amplitude $\sigma_{\mathrm{a}}=150 \mathrm{MPa}$ with $\mathrm{R}=-1$. The dotted lines are the $\mathrm{Ypper}$ and lower bounds of the data. Most crack decelerations below $5 \times 10$ figucycle occur at crack lengths less than $0.1 \mathrm{~mm}$. The full line in the figure was derived from the da/dN vs. $\mathrm{K}_{\max }$ relation for large cracks by assuming that the crack is semi-circular. The oroken line is the da/dn is. $\mathrm{K}_{\text {eff }}$ relation for large cracks. The scales of $k_{\text {max }}$ and $\Delta k_{\text {eff }}$ are top abscissa. For small Stage 1 cracks, the crack groltato for large higher than that predicted from the da/dN $v s$. $\Delta \mathrm{K}_{\text {eff }}$ relon diminishes and the cracks. The scatter of the data in da/dN vo. a relation lenth of about to the large-craçk growth law at a crack length of about data converge to the large $10^{-8} \mathrm{~m} / \mathrm{cycle}$.

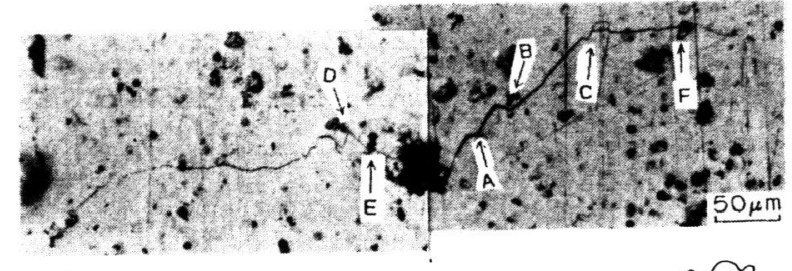

(a)

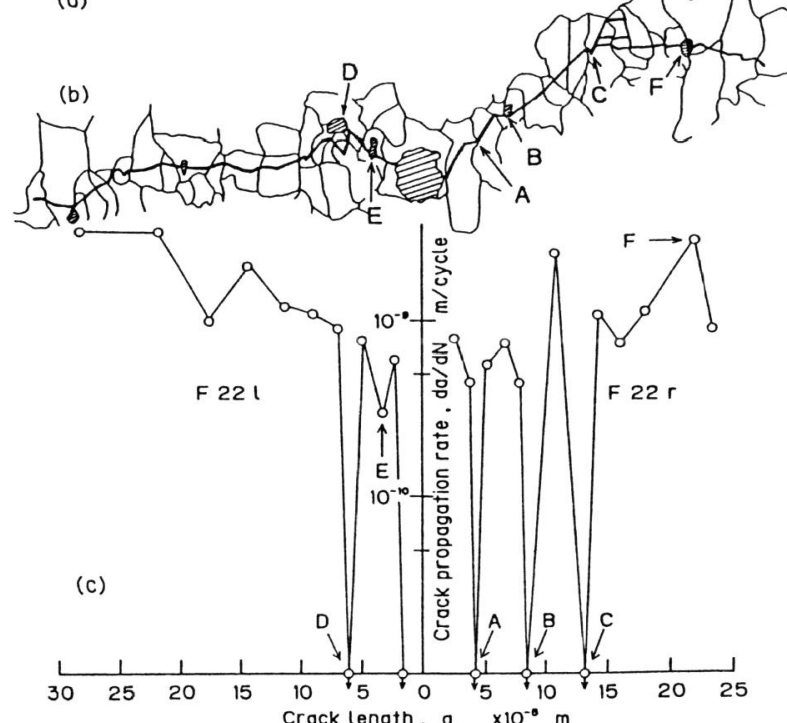

Fig. 14. Propagation of a smal1 surface crack in 2024-T3 alloy. (a) Micrograph, (b) Sketch of the crack and microstructure, (c) Crack growth rate

For life prediction, it is important to predict the propagation behaviour of a main crack which will cause the final separation of components. In Fig.15(b), the propagation rate of the main crack (full curve) is shown together with the average (chain curve) and the bounds (dotted curves) of smal1-crack growth rates. The propagation rate of the main crack is generally higher than the average rate. A crack which encounters fewer blockages becomes the main crack.

\section{Microstructurally Small Cracks}

For microstructurally small cracks, the resistance to crack growth is much influenced by the material microstructure such as the grain orientation and grain boundary. The crack growth rate will be different even when the crack is subjected to the same loading parameter of continuum mechanics ( $\Delta \mathrm{K}$ force. 


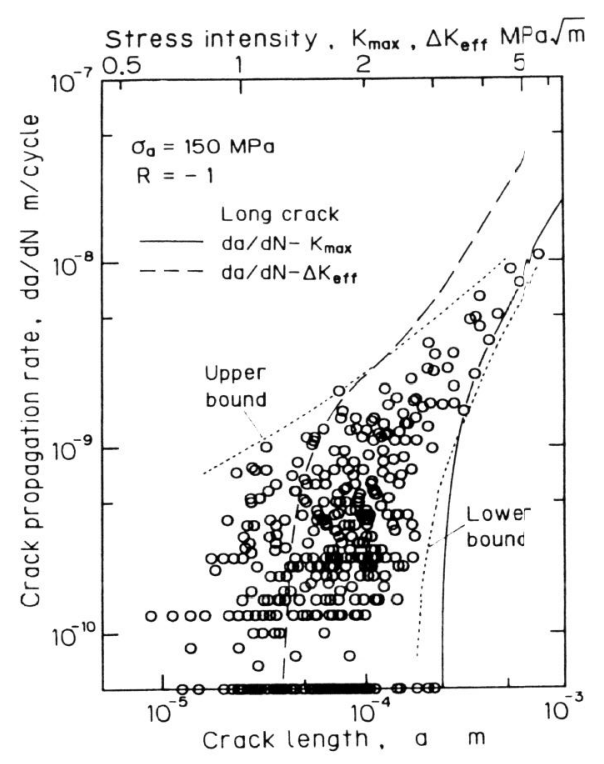

(a) All cracks examined

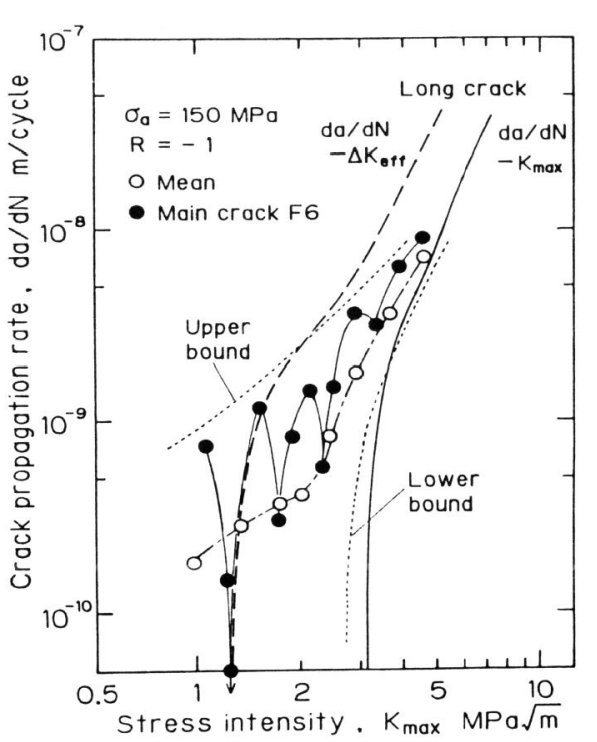

(b) Main crack

Fig. 15. Relation between crack propagation rate and crack length for 2024-T3 alloy.
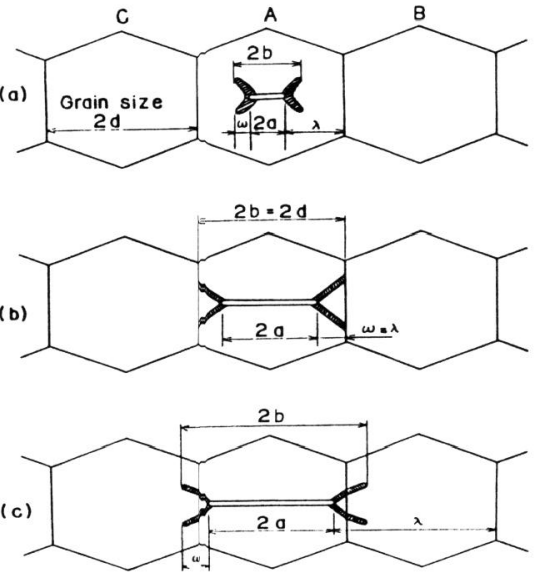

Fig. 16. Model Eor Stage II crack growth.

The interaction of a propagating crack with grain boundaries has been Thodeled by several investigators (Chan et al., 1983, Rios et al., 1985, Tanaka et al, 1986b). The grain boundary acts as the barrier for slip propagation into adjacent grains near the tips of Stage I and II cracks. Figure 16 shows a Stage II crack propagating through a horizontal array of grains. In Fig.16(a), the slip band zone $\omega$ is smaller than the distance $\lambda$ between the crack tip and the grain boundary; the slip band does not reach the grain boundary. In Fig.16(b), the slip bands are blocked by the grain boundary with $\omega=\lambda$. As the crack grows, the slip bands propagate into the ad jacent grains $B$ and $C$ as shown blocking by the grain boundarles depends on the difficulty of generating slip in the adjacent grains near the tips of the blocked slip bands.

By neglecting elastic anisotropy, the range of the crack-tip opening disBeglion theory. Tanaka etal. (1986b) assumed the crack growth rate as a power function of $\triangle C T O D$ as

$$
\mathrm{da} / \mathrm{dN}=\mathrm{A}(\triangle \mathrm{CTOD})^{\mathrm{n}}
$$

and derived irregular growth of microstructurally small cracks. Crack decelerate as they approach the grain boundary.

A Monte Carlo simulation was conducted for fatigue crack growth by assuming the grain size and the frictional stress of each grain as random variables following the two-parameter Weibull distribution (Akiniwa et al., 1988c). Figure $17(\mathrm{a})$ shows the behayiour of $\triangle \mathrm{CTOD}$ of a propagating crack for the

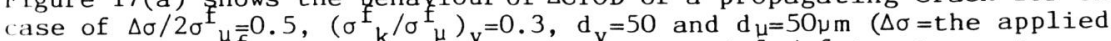
stress range, $\sigma_{j}=$ the mean frictional stress, $\left(\sigma_{\mathrm{k}} / \sigma \mathrm{f}_{\mathrm{u}}\right)_{\mathrm{v}}=$ the variance of the frictional stress relative to the mean value, $d_{\mu}=$ the mean grain size, $d_{v}=$ the variance of the grain size). The crack propagates over six grains

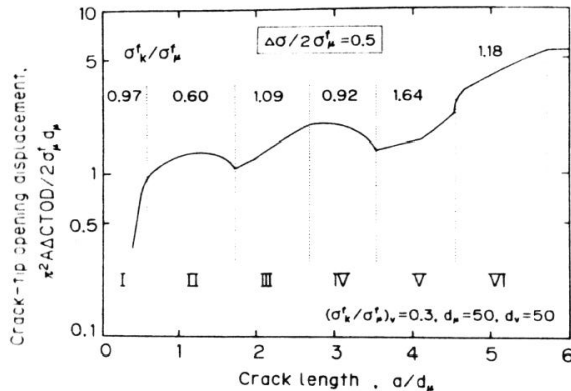

(a) Change of $\triangle$ CTOD with crack length.

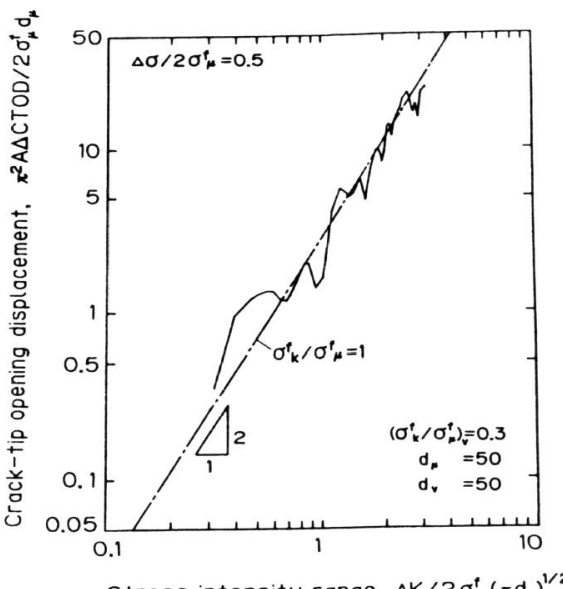

Stress intensity range, $\Delta K / 2 \sigma_{\mu}^{t}\left(\pi d_{\mu}\right)^{1 / 2}$ (b) Relation between $\triangle C T O D$ and $\triangle K$. small cracks. 
whose relative frictional stresses $\sigma^{\mathrm{f}} \mathrm{k}^{/} \sigma_{\mu}^{\mathrm{f}}$ are given in the figure. The blocking effect of the grain boundary is neglected in the simula crack decelerates when the next grain has a higher ${ }^{\mathrm{f}} \sqrt{\pi \mathrm{d}} \mathrm{ional}$. The chain curve is the $\triangle$ CTOD value for $\sigma{ }_{k}=\sigma \mu$ and has a slope of two in the $10 \mathrm{og}-10 \mathrm{~g}$ diagram. The scatter of the growth rate diminishes with crack growth, approaching the chain line.

Figure $18(\mathrm{a})$ shows the $\triangle \mathrm{CTOD}$ vs. $\triangle \mathrm{K}$ relations obtained from 30 cracks. The scatter diminishes as the crack grows, which agrees with the experimental results shown in Fig.15(a). For very small cracks, the scatter is larger in experiments. In reality, a very small crack grows in a Stage 1 fashion and the grain boundary blocks the crack growth. By assuming the exponent $\mathrm{n}=1$ in eq. (9), the number of cycles spent for propagating a crack to a length of 500 $\mu \mathrm{m}$ can be calculated for 40 cracks. In Fig. 18(b), the $\triangle C T O D$ behaviour of the fastest crack is drawn with the full line and that of the slowest one with the dotted line. At short crack lengths, the difference in $\triangle C T O D$ between the fastest and slowest cracks is large. The effects of the distributions of the grain size and the frictional stress on the growth rate of small cracks can be evaluated by this simulation. The effect of the strength of the boundary blocking
simulation (Akiniwa et al., 1988c).

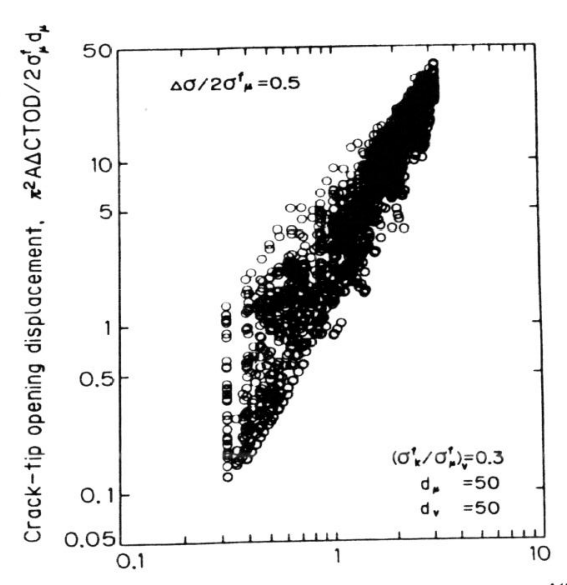

Stress intensity range, $\Delta K / 2 \sigma_{\mu}^{t}\left(\pi d_{\mu}\right)^{1 / 2}$

(a) 30 cracks

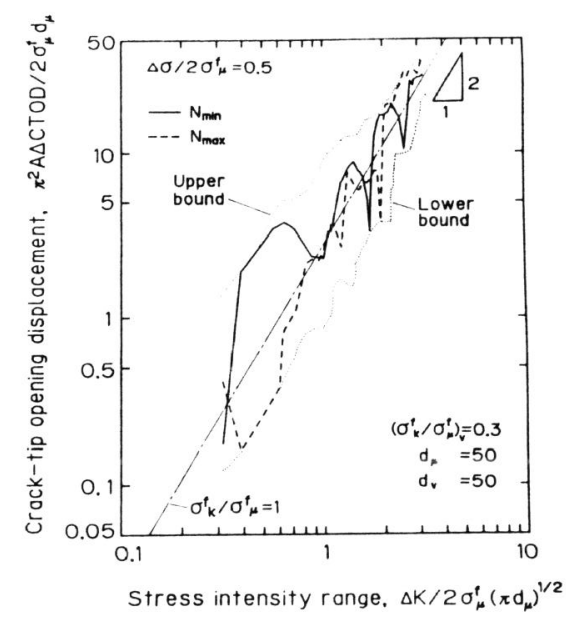

(b) Fastest and slowest cracks Fig. 18, Relation between $\triangle \mathrm{CTOD}$ and $\triangle \mathrm{K}$. mined (Akiniwa et al., 1988a). Figure 19 shows the crack growth rate plotted against $K_{\max }$ and $\Delta \mathrm{K}_{\mathrm{eff}}$. Most of the data lie left to the da/dN $v s$. cracks smaller than about $100 \mu \mathrm{m}$.

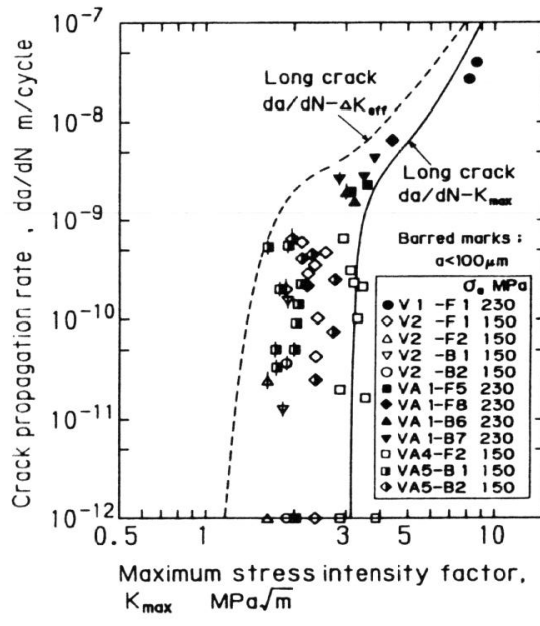

(a) da/dN vs. $K_{\max }$

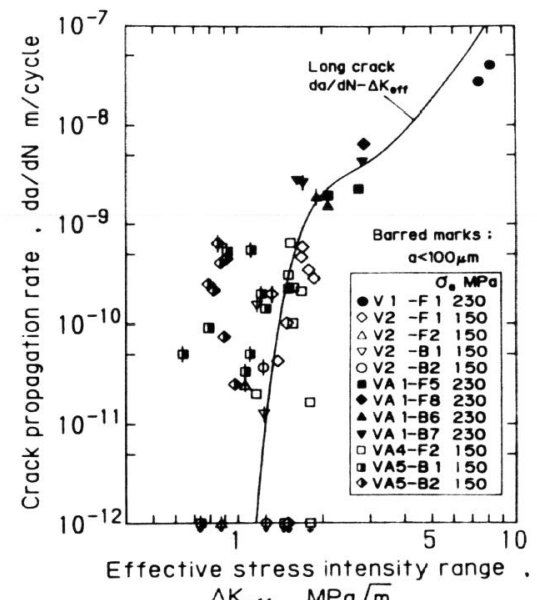

$\Delta \mathrm{K}_{\text {eft }} \mathrm{MPa} \sqrt{\mathrm{m}}$ Relation between crack propagation rate and stress intensity ranges.

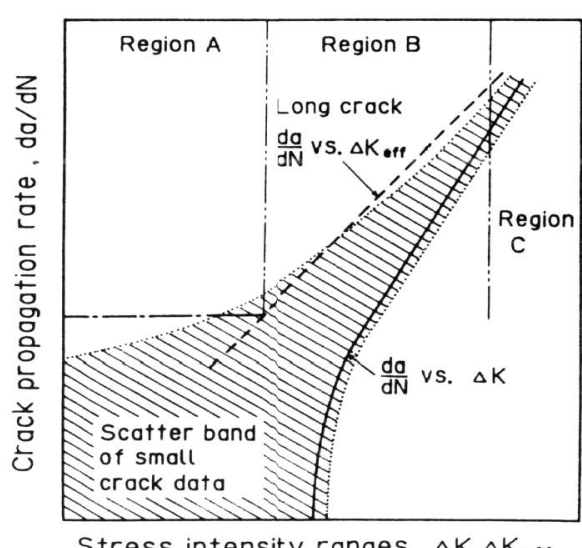

Fig. 20. Relation between crack propagation rate and stress intensity ranges.
The crack closure also plays an important role for small crack growth. Sharpe et al. (1988) used the laser interferometric method to measure the crack opening displacement of a small crack. The same method was applied to small cracks in 2024-T3 alloy and the crack opening stress was deter- 
For life prediction, the relation between the crack growth rate and the crack length is necessary. Based on the experimental results on small fatigue cracks in 2024-T3 aluminum alloy, the relation can be divided into three regions as shown in Fig. 20. In Region C, where the crack growth rate was higher than $10^{-} \mathrm{m} / \mathrm{cycle}$, the growth data followed the da/dN vs. $\Delta \mathrm{K}$ relation for large cracks and the scatter in the crack growth rate was small. In Region A, where the crack length was less than $0.1 \mathrm{~mm}$, the crack grew along slip planes and the scatter of the crack growth rate was large. In Region B, the crack growth path was perpendicular to the stress axis; the crack growth rate was higher than that predicted form the da/dN vs. $\Delta \mathrm{K}$ relation because of premature crack closure, but lower than da/dN vs. $\Delta K_{\text {eff }}$
relation. Tokaji et al. (1986) used a similar division of the crack length regime in their studies of steels.

For Regions A and B, the scatter of the fatigue crack growth rate can be treated statistically; the life prediction based on the average growth becan be obtained by using the constant rate for Region $A$ (chain line) and

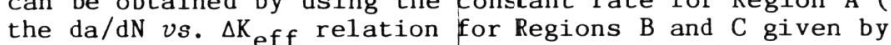

$$
\mathrm{da} / \mathrm{dN}=\mathrm{C}^{\prime}\left(\Delta \mathrm{K}_{\text {eff }}\right)^{\mathrm{m}^{\prime}}
$$

The transition from Region A to E coincides with the transition in growth mode from Stage I to II. The distribution of the fatigue life can be esion has been suggested by Kendall et al. (1986) and Herman et al. (1988).

\section{Fatigue Failure Diagram}

The growth threshold of a mechanically small crack such as a notch-tip crack is given by a constant value of $\Delta \mathrm{K}_{\text {eff }}$. On the other hand, for microstructurally small crack, $\Delta \mathrm{K}_{\mathrm{eff}}$ is not a constant value. A loca parameter such as the true SIF value which is the subtraction of the shielding SIF value from the applied SIF value is necessary to derive the threshold condition (Yokobori et al., 1988). Engineering judgment of the possibility of fatigue failure is based on the diagram such as shown in Figs.7 and 8. For a pre-cracked specimen, the diagram between the threshold stress and the crack size proposed by Kitagawa et al. (1976) will tion threshold and the non-propagation threshold.

The crack growth behaviour from a pre-crack in smooth or notched specimens was studied with mild steel (SM41B) (Tanaka et al., 1988c). Cracks were made under a stress amplitude higher than the fatigue limit and then

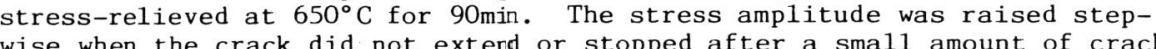
we whion. The stress-relief of the specimen was repeated before the applied stress was raised. Figure 21 shows the result for three cracks. Two small cracks are surface cracks and the longest is a through-thickness crack in the center of a plate. All three cracks start to grow when the maximum SIF value $K_{\text {ix }}$ is equal to $\Delta \mathrm{K}_{\text {f }} \mathrm{f}_{\text {tho }}$ for long cracks. Continuous propagation takes place even at $K_{\text {max }}$ less than $\Delta K_{\text {tho }}$ for long cracks. The diagram can be divided into three regions: no-growth, arrest and continuous propagation. At the stress amplitude above the horizontal line corresponding to the fatigue limit, the fracture takes place in the specimen even without pre-cracks. The arrest of a propagating crack in pre-cracked specimens can also be analysed on the basis of the R-curve method.

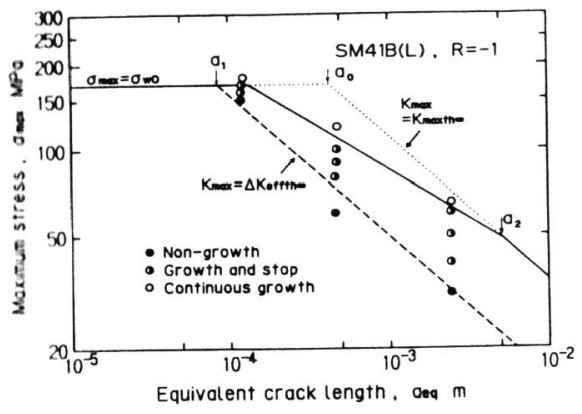

Fig. 21. Fatigue crack

propagation from pre-

crack for mild steel

(SM41B).

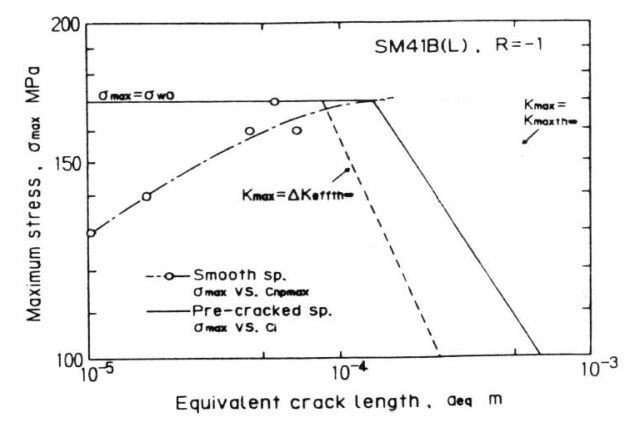

(a)

ig. 22. Non-propagating fatigued below the fatigue limit for mild steel (SM41B).

The fatigue 1 imit of smooth specimens is determined by the propagation
threshold of a nucleated crack. Non-propagating cracks in smooth specimens of mild steel (SM41B) fatigued below the fatigue 1 imit were examined and the longest one was determined (Tanaka et al., 1988b). In Fig.22, the longest crack length $c$ is plotted against $\sigma_{\max }$, together with a similar relation for pre-cracked specimens. The stress amplitude corresponding to the intersection of $\sigma_{\max } v s . c_{n p m a x}$ and $\sigma_{\max } v s . c_{i}$ curves is the fatigue limit $\sigma_{w 0}$ as proposed by Brown (1986). Cracks made under the fatigue limit were most1y Stage I cracks which could propagate at SIF values even below $\Delta K_{\text {eff tho }}$

\section{CONCLUSIONS}

(1) The effective stress intensity range $\Delta K_{\text {eff }}$ can be used as a crack driving force parameter for mechanically short cracks formed at the root of notches. The threshold value of the effective stress intensity range $\Delta \mathrm{K}_{\text {effth }}$ was found to be constant,
geometry or loading conditions.

(2) A resistance-curve method was proposed for predicting the growth threshold of short fatigue cracks near the notch root. The resistance
curve was constructed in terms of the threshold value of the maximum stress intensity factor which was the sum of the $\Delta \mathrm{K}_{\mathrm{effth}}$ value and the crack opening stress intensity factor $\mathrm{K}_{\text {opth }}$ determined experimentally as a function of crack length. The curve was independent of notch geometry, but dependent on the mean stress and materials.

(3) The effects of material, notch geometry and mean stress on the growth threshold of short crack at notches and on the fatigue strength of notched specimens were successfully predicted by the resistance-curve method.

(4) Both crack closure and microstructural inhomogeneity are responsible for the fast, irregular growth behaviour of microstructurally small 
fatigue cracks nucleated in smooth specimens. The relation between the crack growth rate and the crack length was divided into three regions: $\mathrm{A}, \mathrm{B}$ and $\mathrm{C}$. In Region $\mathrm{C}$, where the crack growth rate was higher than $10^{-} \mathrm{m} / \mathrm{cycle}^{-1}$, the crack growth data followed the da/dN vs. $\Delta \mathrm{K}$ relation for large cracks and the scatter in the crack growth rate was small. In Region A, where the crack length was less than $0.1 \mathrm{~mm}$, the crack grew along slip planes and the scatter of the crack growth rate was large. In Region $B$, the crack growth path was perpendicular to the stress axis; the crack growth rate was higher than that predicted from the $\mathrm{da} / \mathrm{dN}$ vs. $\Delta \mathrm{K}$ relation because of premature crack closure.

(5) A Monte Carlo simulation for small fatigue crack growth was conducted by assuming the grain size and the frictional stress of each grain as random variables in our micromechanical model of crack-tip slip bands interacting with the grain boundary. The statistical characteristics of simulated crack gron

(6) For engineering proposes, a simple method for predicting the propagation life of smal1 fatigue cracks was proposed based on the observed relation between the crack growth rate and the stress intensity range. The fatigue fracture diagram was construt stresses for non-growth, arrest and continuous growth of small cracks specimen was discussed based on this fitigut

\section{ACKNOWLEDGEMENT}

Support of this work by The Kurata Research Grant is gratefully acknowledged.

\section{REFERENCES}

Akiniwa, Y., M. Kinefuchi and K. Tanaka (1988a). Crack closure behavior of small fatigue surface crack studied with interferometric strain/displacement gage. Proc. 25th X-Ray Symp., Soci. Mater. Sci. Jpn, $153-158$

Akiniwa, Y., K. Tanaka and E. Matsui (1988b). Statistical characteristics of propagation of small fatigue cracks in smooth specimens of aluminium alloy 2024-T3. Mater. Sci. Eng., To be published.

kiniwa, Y. and K. Tanaka (1988c). Simulation of propagation of small fatigue surface cracks. Preprint of 19th Symp. Fatigue, Soci. Mater.

Akiniwa, Y., K. Tanaka and N. Taniguchi (1988d). Propagation and closure of short fatigue cracks at notches under compres
Fatigue Fract. Eng. Mater. Struct., 11, 343-354.

Akiniwa, Y., K. Tanaka and N. Taniguchi $(1988 \mathrm{e})$. Prediction of propagation and nonpropagation of short fatigue cracks at notches under prope and nonpropagation of short fatigue cracks at notches under mean
stresses. Trans. Jpn Soci. Mech. Eng., Paper No.88-0328A. To be published.

Brown, M.W. (1986). Interfaces between short, long, and non-propagating cracks. In: The Behaviour of Short Fatigue Cracks (K.J. Miller and E.R. de los Rios ed.), pp.423-439, Mech. Eng. Pub1. Ltd., London.

Chan, K.S. and J. Lankford (1983). A crack-tip strain model for the growth of small fatigue cracks. Scripta Met., 17, 529-532.

Herman, W.A., R.W. Hertzberg and R. Jaccard (1988). A simplified laboratory approach for the prediction of short crack behaviour in Holm, D.K., A.F. B1om and S. Suresh (1986). Growth of cracks under farfield cyclic compressive loads: numerical and experimental results. Eng. Fract. Mech., 23, 1097-1106.

Kenda11, J.M., M.N. James and J.F. Knott (1986). The behaviour of physically short fatigue cracks in sheets. In: The Behaviour of Short Fatigue Cracks (K.J. Miller and E.R. de los Rios ed.), pp.241-258, Mech. Eng. Publ. Ltd., London.

Kitagawa, H. and S. Takahashi (1976). Application of fracture mechanics to very small cracks or the cracks in ear1y stage. Proc. 2nd Int. Conf. Mech. Behv. Mater., Boston, pp.627-631, ASM.

McEvily Jr., A.J. and K. Minakawa (1987). On the crack closure and the

notch size effect in fatigue. Eng. Fract. Mech., 28, 519-527.

Murakami, Y. and T. Endo (1980). Effects of small defects on fatigue

strength of metals. Int. J. Fatigue, 2, 23-30.

Newman Jr., J.C. (1982). Behaviour of short cracks in airframe components. Adv. Group Aero. Res. Dev. Conf. Proc. No.328. 6.1-6.26.

Nishikawa, I., M. Konishi, Y. Miyoshi and K. Ogura (1986). Small fatigue crack growth at notch root in elastic-plastic range. $J$. Soci. Mater. Sci., Jpn, 35 , 904-910.

Nisitani, H. (1981). Unifying treatment of fatigue crack growth laws in small, large and non-propagating cracks. In: Mechanics of Fatigue (T.

Mura, ed.), AMD, Nol.47, pp.151-166, AsMe, New York.

Rios, E.R., H.J. Mohamed and K.J. Miller (1985). A micro-mechanics Fatigue Fract. Eng. Mater. Stmuct., $-49-63$.

X. Su (1988). Closure measurements of naturally initiating sma11 cracks. Eng. Fract. Mech., 30, 275-294.

Suresh, S. and R.O. Ritchie (1984). The propagation of short fatigue cracks. Inter. Metal Rev., 29, 445-476.

Tanaka, K. and Y. Nakai (1983). Propagation and non propagation of short fatigue
$315-327$

Tanaka, K. and Y. Akiniwa (1986a). Notch-plasticity effect on closure of short fatigue cracks. Trans. Jpn Soci. Mech. Eng., 52, 1741-1748.

Tanaka, K., Y. Akiniwa, Y. Nakai and R.P. Wei (1986b). Modelling of small fatigue crack growht ineracting with grain boundary. Eng. Fract. Mech., 24, 803-819.

Tanaka, K. (1987). Mechanisms and mechanics of short fatigue crack propagation. JSME Inter. J., 35, 1-13.

Tanaka, K. and Y. Akiniwa (1988a). Resistance-curve method for predicting propagation threshold of short fatigue cracks at notches. Eng. Fract. Mech., 30, 863-876.

Tanaka, K., Y. Akiniwa and M. Nakao (1988b). The relation between the growth threshold of small cracks and the fatigue limit of smooth specimens. Preprint of 37th Mtg. Of Mater. Sci. Jpn, 19-21.

Tokaji, K., T. Ogawa, Y. Harada and Z. Ando (1986). Limitations of linear elastic fracture mechanics in respect of small fatigue cracks and microstructure. Fatigue Fract. Eng. Mater. Stmuct., 9, 1-14.

Yokobori Jr., A.T., T. Isogai and T. Yokobori (1988). Micromechanics zone. Proce of JSME 65th Mtg., Paper No.87-1246A. 